\title{
Von Hyp- und Anästhesierten
}

Enrico Danieli

Korrespondenz:

Dr. med. Enrico Danieli

Via ai Colli 22

CH-6648 Minusio
Sie gehen, ohne nach rechts oder nach links zu schauen, durch die Welt, ihr Kennzeichen ist ihre Unberührbarkeit oder ihre Empfindungslosigkeit: Nach aussen wirken sie gefestigt, aufrecht, klar, und so gibt es nichts, das sie aus der Bahn werfen könnte. Sie rechnen mit allem und können demnach von nichts überrascht werden, ihre Welt ist weder gut noch böse, sie ist, und damit hat es sich. Sie sind freundlich und unnahbar, sie sind die geborenen und stets unbeteiligten Zuschauer, und in dieser Rolle bleiben sie sich treu: Würde Hilfe gefordert, gingen sie weiter, nicht aus böser Absicht, sondern aus Unaufmerksamkeit, Uninteressiertheit, Gleichgültigkeit. Es ist nicht die Gewissenlosigkeit, die sie leitet, sondern die Gedankenlosigkeit. Sie sind, obwohl stets anwesend, nicht greifbar, sie sind, obwohl anwesend, doch abwesend. Sie genügen sich selbst, stellen sich nicht in Frage, weil es nichts in Frage zu stellen gibt. Ihre Seelen sind rein, ihre Leben unbefleckt. Ihre Gefühle sind die der Kälte, die der frühzeitigen Vergreisung, sie erscheinen ohne Gefühl, also gefühllos, ohne Affekte wie Wut oder Trauer (hyp- oder anästhesiert). In ihrer Unfassbarkeit sind sie langweilig, sind uns nicht fremd, sondern fern in ihrer unendlichen Distanziertheit. Ohnmacht, Scham oder gar Schuld sind ihnen unbekannt. Sie funktionieren nach mechanischen Prinzipien, die sie sich selbst auferlegen oder die ihnen die Gesellschaft auferlegt. Ein moralisches Engagement existiert nicht. In ihrem Sog marschieren ihre Schattenbilder millionenfach, verführbar, da ohne Ansprüche, irrational, da ohne Moral, gefährlich, da ohne Willen. Es ist, als wären sie längst schon tot und bewegten sich doch, kreiseziehend, immer weiter, nicht im Licht der Sonne, sondern im Reich des Schattens. Sie erwarten nichts, haben keine Vergangenheit und keine Zukunft, leben ohne jede Einschränkung einzig im Jetzt. Sie verkörpern einen speziellen Typus Mensch: den heutigen. Sie leben nicht mit- oder gegeneinander, sondern nebeneinander. Hätten wir an entsprechenden Orten nach ihnen zu suchen, wir würden sie finden in Wüsten, in Vorhöllen, in Vororten, in Einkaufsschlangen, in Warteschlaufen, in Stauräumen, in Einkaufszentren/Wohnsiedlungen/Stadien.

Werden wir, lesen wir diese Beschreibung der Gefühllosen und Gleichgültigen, nicht ein wenig seltsam berührt? Ist, fragen wir uns, das denn nicht schon eine Krankheit? Müssten wir nicht entsprechende Abklärungen in die Wege leiten, gewisse Krankheiten zumindest der Form nach ausschliessen? Denn ohne Zweifel werden wir bei diesen erwähnten Stigmata an spezielle Verläufe von Depressionen erinnert.

«Je älter ich werde», schreibt Byron, «desto gleichgültiger auch, nicht dem Leben selbst gegenüber ..., sondern gegenüber allem.» Byron, ein berühmter Melancholiker, er müsste es wissen. Die Melancholiker ziehen sich in ihre eigene Welt zurück, die Gleichgültigkeit verschlingt alles mit Verlust: des Interesses, des Glaubens, des Wollens. Der Melancholiker jedoch weiss um diesen Verlust, der früher oder später alles erfasst, daher die schwerverständliche Symptomatologie sowohl der Unempfindlichkeit - weder Trauer noch Freude kann empfunden werden (C. F. Meyer: «Nichts, das mich verdross! Nichts, das mich freute! Niederrinnt ein schmerzenloses Heute!», in der Urfassung ist gar vom schmerzenlosen Tod die Rede) - wie auch der Überempfindlichkeit (sog. Anaesthesia dolorosa): Minderwertigkeitsgefühle, Hypochondrie, Selbstvorwürfe usw. Diese Doppelung im Empfinden bedeutet, dass der Melancholiker die Welt als stetigen Verlust erlebt (also als stetigen Tod). Nichts entgeht seiner (auf sich selbst gerichteten) Aufmerksamkeit, und gleichzeitig verschwimmt ihm alles vor Augen (im Tränenschleier): innere Leere (Depersonalisation), das Nichts, der Tod. Kleist: «Nichts kann trauriger sein [...] als diese Stellung in der Welt; der einsame Mittelpunkt in einem einsamen Kreis.» Er, der Melancholiker, fürchtet sich und die ganze Welt. Der Welt tritt er mit Widerwillen entgegen. Entscheidend ist, dass die Melancholiker nicht von keinem Gefühl, sondern von einem negativen (Kummer, Angst usw.) beherrscht werden. Melancholiker leiden ohne Ende, vom ewigen Grübeln wird ihre Seele zermartert. Weltschmerz nennen wir diesen Zustand, der nichts als Mangel ist: lebenslanges Unbefriedigtsein. Leben wollen sie nicht, und sterben können sie nicht. Sie sind voller Hass, am hassenswertesten ist ihnen ihr eigenes missratenes Leben. Ihre Gefühle sind vollkommen mit Negativität behaftet, sie sind demgemäss keineswegs gefühllos: Der Lebensekel ist omnipräsent. Auch sind sie, doch auf andere Weise als die Gleichgültigen, unnahbar, denn ihre Welt ist eine nur ihnen eigene ausserhalb der Orte und der Zeiten: Sie wären, hätten wir sie zu suchen, einsam und verlassen im Niemandsland (im Niemandsnichts) zu finden. 